\title{
Impacto do aquecimento global no cultivo do feijão-caupi, no Estado da Paraíba
}

\author{
João H. B. da C. Campos ${ }^{1}$, Madson T. Silva ${ }^{1} \&$ Vicente de P. R. da Silva ${ }^{1}$
}

RESUMO

No presente estudo se avaliam os impactos da mudança do clima com base nos relatórios do Painel Intergovernamental em Mudanças do Clima (IPCC), no zoneamento agrícola de riscos climáticos para a cultura do feijão-caupi Vigna unguiculata L. Walp) cultivado em sistema de sequeiro, no Estado da Paraíba. Utilizou-se o modelo do balanço hídrico associado a técnicas de geoprocessamento, e se objetivou a identificação das regiões do Estado em que a cultura do feijão-caupi sofrerá restrições em face das mudanças climáticas. As variáveis consideradas no modelo foram precipitação pluvial, coeficientes de cultura, evapotranspiração potencial e duração das fases fenológicas da cultura. Adotou-se, como limite para o índice de satisfação da necessidade de água para a cultura (ISNA), o valor de 0,50. A data foi considerada adequada para a semeadura quando a simulação do balanço hídrico apresentou resultados de ISN A com frequência mínima de $80 \%$, superior ao valor do critério adotado. Tendo em vista um aumento de temperatura do ar de 3 e $6{ }^{\circ} \mathrm{C}$, como sugerido pelo IPCC, o cultivo do feijão-caupi sofrerá uma redução significativa nas áreas atualmente favoráveis ao seu cultivo no Estado da Paraíba.

Palavras-chave: precipitação pluvial, ISN A, modelo do balanço hídrico

\section{Impact of global warming on the cowpea cultivation in the State of Paraíba}

\begin{abstract}
This study evaluates the impacts of climate change, based on the reports of the IPCC, on the agricultural zoning of climatic risk of the rainfed cowpea (Vigna unguiculata L. Walp) crop grown in the Paraíba state. The water balance model combined with GIS techniques was used for identifying areas in the state where the cowpea crop will suffer yield restrictions due to climate changes. Model input variables were: rainfall, crop coefficients, potential evapotranspiration and duration of the crop cycle. The limit value of 0.5 was adopted for the water requirement satisfaction index (W RSI). The date acceptable for seeding was that when the water balance simulation presented, for at least $80 \%$ minimum frequency, WRSI value greater than that limit value. An increase in air temperature of 3 and $6{ }^{\circ} \mathrm{C}$, as suggested by the IPCC, will cause a significant reduction in the areas currently favorable for cowpea crop growth in the Paraíba state.
\end{abstract}

Key words: rainfall, WRSI, water balance model 


\section{INTRODUÇãO}

No século XX ocorreu um aumento de $0,65^{\circ} \mathrm{C}$ na média da temperatura global, mais pronunciado na década de 90 (IPCC, 2001). Durante este período a precipitação pluvial teve um incremento de 0,2 a $0,3 \%$ na região tropical e, do ponto de vista global, as prováveis causas dessas mudanças entre o sistema terra-atmosfera-oceano são estudadas levando-se em conta suas forçantes e os mecanismos de interação. As causas desta variação podem ser de ordem natural, causada pelo homem (antropogênica) ou uma soma das duas (Silva, 2004). O relatório do IPCC (2001) indica, por meio de modelos matemáticos baseados em dados registrados nos Oceanos, Biosfera e Atmosfera, um aumento entre 1,4 e $5,8^{\circ} \mathrm{C}$ da temperatura global até o final do século XXI. As magnitudes de tais previsões são ainda incertas visto que pouco se sabe em relação aos processos de troca de calor, de carbono e de radiação entre os diversos setores do sistema terra-atmosfera.

Os modelos de simulação do sistema solo-planta-atmosfera constituem uma ferramenta adequada para estudos que envolvem aplicações sob condições de grande variabilidade ambiental, pois permitem determinar os riscos envolvidos na produção agrícola em função dos principais componentes de produção (Cunha \& Assad, 2001; Sultan et al., 2005). Eles possibilitam a repetição de diferentes condições de manejo em vários anos e locais, usando-se dados climáticos históricos ou sintéticos (Harrison et al., 1989; Kenny \& Harrison, 1992).

A definição de culturas resistentes às condições edafoclimáticas reinantes na maior parte do semiárido é de grande importância, visto que a possibilidade de sucesso na colheita dos pequenos e grandes agricultores se torna maior à medida em que os riscos climáticos são minimizados (Jones \& Thornton, 2003; Jarvis et al., 2008). O desenvolvimento do zoneamento agrícola constitui uma ferramenta atraves da qual se busca a minimização dos riscos mais frequentes que a cultura poderá sofrer no período de plantio até a sua colheita (Zullo Júnior et al., 2006). Para a região semiárida do Brasil e devido à grande irreguralidade do seu regime pluviométrico, a conciliação dos períodos chuvosos e as melhores épocas de plantio são fatores determinantes para o sucesso da exploração agrícola de uma cultura. A irregularidade do período chuvoso na região Nordeste do Brasil restringe a escolha de qualquer cultura a ser implantada, principalmente na maior parte do semiárido, justamente onde o déficit hídrico é ainda maior (Silva et al., 2005).

Vários estudos evidenciam que a definição das épocas de semeadura por meio do balanço hídrico do solo contribui para reduzir o risco climático causado pela distribuição irregular das chuvas (Silva \& Azevedo, 2000; Silva \& Amaral, 2007; Andrade Júnior et al., 2001; 2004); entretanto, no caso do Estado da Paraíba e em especial com a cultura de feijão-caupi, praticamente inexistem estudos específicos para as diferentes mesorregiões do Estado; desta forma e tendo em vista a importância da agricultura para a economia brasileira, faz-se oportuna a avaliação do impacto das mudanças climáticas sobre as culturas plantadas em sistema de sequeiro. Neste contex- to se analisam, no presente estudo, os impactos específicos do aumento da temperatura do ar no zoneamento agrícola de riscos climáticos para a cultura do feijão-caupi cultivado em sistema de sequeiro no Estado da Paraíba, através de um modelo de balanço hídrico, razão por que se pretende, com este trabalho, identificar os riscos climáticos associados ao cultivo do feijão-caupi de sequeiro nas microrregiões do Estado da Paraíba, de acordo com os cenários de aumento de temperatura do ar propostos pelo IPCC.

\section{MATERIAL E MÉTODOS}

\section{Características da cultura}

O feijão-caupi é uma leguminosa bem adaptada às condições edafoclimáticas do Nordeste do Brasil (NEB). Esta leguminosa é cultivada para a produção de grãos em regiões de clima quente, úmido e semiárida, para alimentação humana e animal (Ellis et al., 1994).

O feijão-caupi ocupa $60 \%$ das áreas cultivadas com feijão no NEB. Os níveis de produtividade são, em média, inferiores aos do feijão comum. A grande maioria dos produtores dessa cultura se compõe de pequenos agricultores os quais, em sistema de consórcio, associam outras culturas comuns à região. No Estado da Paraíba ela é cultivada em quase todas as microrregiões, detendo $75 \%$ das áreas de cultivo com feijão (IBGE, 2008). Trata-se de uma cultura de produtividade considerável cujos valores variam entre 300 e $700 \mathrm{~kg} \mathrm{ha}^{-1}$, em diferentes regiões do Estado. As mesorregiões do Agreste e do Sertão paraibano se destacam pelos plantios de baixa, média e larga escalas, juntamente em consórcio com culturas mais tradicionais, como o milho e o algodão. Do ponto de vista pluviométrico, as exigências hídricas são consideravelmente satisfeitas, visto que exigem um mínimo de $300 \mathrm{~mm}$ de precipitação pluvial que, se bem distribuídos durante o período de desenvolvimento da cultura, oferece boa colheita; assim, até mesmo as microrregiões do Estado que possuem registros pluviométricos médios entre 300 e 500 mm, são favoráveis ao cultivo da leguminosa, enquanto as médias mensais entre 22 e $25^{\circ} \mathrm{C}$ durante o ciclo vegetativo da cultura constituem uma faixa térmica ideal para o bom desenvolvimento da planta. Altas temperaturas durante o florescimento reduzem o pegamento floral, prejudicando a floração e a produção final. Considerando-se a faixa ótima as temperaturas entre $20 \mathrm{e}$ $30^{\circ} \mathrm{C}$, baixas temperaturas, inferiores a $19^{\circ} \mathrm{C}$, influenciam diretamente o comprometimento da produtividade da leguminosa, dando margem ao aumento do ciclo vegetativo e retardando o florescimento; temperaturas superiores a $35{ }^{\circ} \mathrm{C}$ também acarretam prejuízos ao desenvolvimento da cultura pois provocam aborto espontâneo das flores, ocasionam a retenção das vagens na planta e diminuem consideravelmente o número de sementes por vagem.

\section{Área de estudo}

O Estado da Paraíba está localizado na porção oriental da Região Nordeste do Brasil, entre os meridianos de $34^{\circ} 54^{\prime} 54^{\prime \prime}$ e $38^{\circ} 45^{\prime} 45^{\prime \prime}$ de longitude a oeste de Greenwich e os parale- 
los de $6^{\circ} 02^{\prime} 12^{\prime \prime}$ e $8^{\circ} 19^{\prime} 18^{\prime \prime}$ de latitude sul e sua área é de $56.439 \mathrm{~km}^{2}$. Segundo a classificação de Köppen, aqui predomina o seguinte tipo climático: As'-quente e úmido, com chuva de outono-inverno; a época chuvosa tem início nos meses de fevereiro a março e duração até julho/agosto, com período de estiagem de setembro a fevereiro, a temperatura do ar apresenta valores médios anuais compreendidos entre 22 e $26^{\circ} \mathrm{C}$ (Silva et al., 2006). As maiores precipitações pluviais ocorrem nos meses de janeiro, fevereiro e março, com médias anuais superiores a $600 \mathrm{~mm}$. A estação seca corresponde ao período de maio até dezembro (Brasil, 1972).

\section{Risco climático da cultura}

Obteve-se o risco climático por intermédio do balanço hídrico da cultura, realizado em duas partes, em que na primeira se determina o balanço hídrico, assumindo-se as condições atuais de temperatura do ar e, ainda, os cenários de acréscimo de temperatura de 3 e $6^{\circ} \mathrm{C}$, conforme apresentados pelo (IPCC, 2001), na segunda etapa foram empregados os valores de ISNA (Índice de Satisfação da Necessidade de Água para a cultura) estimados para o período fenológico compreendido entre a floração e o enchimento das vagens (período mais crítico ao déficit hídrico), com frequência mínima de $80 \%$ nos anos utilizados em cada estação pluviométrica. Cada valor do ISNA observado durante esta fase foi associado à localização geográfica da respectiva estação para posterior espacialização, utilizando-se o software SPRING versão 4.2 (Câmara et al., 1996). Determinou-se a simulação da época de semeadura utilizando-se o Sistema de Análise Regional dos Riscos Agroclimáticos, com base no software SARRAZON (Baron et al., 1996).

\section{Variáveis de entrada do modelo SARRAZON}

Precipitação pluvial diária $(\mathrm{P})$ : Obtiveram-se os dados de precipitação pluvial no Banco de Dados Hidroclimatólogicos da Superintendência de Desenvolvimento do Nordeste SUDENE (1990), publicados na Série de "Dados Pluviométricos Mensais do Nordeste - Paraíba”, priorizando-se as séries históricas superiores a 30 anos referentes às informações de 95 postos pluviométricos utilizados neste estudo.

Evapotranspiração real (ETr): O modelo estima a evapotranspiração real (ETr) por uma equação de terceiro grau, proposta por Eagleman (1971), que descreve a evolução da ETr em função da evapotranspiração máxima - ETm e da umidade do solo - HR, expressa como segue:

$$
\mathrm{ETr}=\mathrm{A}+\mathrm{B}(\mathrm{HR})-\mathrm{C}(\mathrm{HR})^{2}+\mathrm{D}(\mathrm{HR})^{3}
$$

em que $\mathrm{A}=0,732-0,05 \mathrm{ETm} ; \mathrm{B}=4,97 \mathrm{ETm}-0,66 \mathrm{ETm}^{2} ; \mathrm{C}=$ 8,57 ETm - 1,56 ETm ${ }^{2}$; D = 4,35 ETm - 0,88 ETm ${ }^{2}$ e HR $=$ umidade do solo.

Evapotranspiração máxima (ETm): Os valores da ETm foram estimados pela equação (Doorenbos \& Kassam, 1979):

$$
\mathrm{ET}_{\mathrm{m}}=\mathrm{P}+\mathrm{I} \pm \mathrm{Qz}-\mathrm{CAD}
$$

em que ETm é a evapotranspiração máxima da cultura ( $\mathrm{mm}$ dia$\left.{ }^{1}\right)$; P a precipitação pluvial (mm dia $\left.{ }^{-1}\right)$; I a irrigação (mm); Qz a infiltração e redistribuição de água no solo (mm) e CAD, a variação de armazenamento de água no solo na camada estudada para o intervalo de tempo considerado no balanço. Por se tratar de uma cultura de sequeiro, a irrigação (I) foi sempre zero.

Evapotranspiração potencial $\left(\mathbf{E T}_{\mathrm{p}}\right)$ : $\mathrm{A} \mathrm{ET}_{\mathrm{p}}$ foi estimada pelo método de Thornthwaite \& Mather (1957) e calculada para cada dez dias do ano, gerando 36 dados de evapotranspiração potencial por ano, pela seguinte equação:

$$
\mathrm{ET}_{\mathrm{p}}=0,533 \mathrm{C}_{\mathrm{j}} \frac{10 \overline{\mathrm{T}}_{\mathrm{a}}}{\mathrm{I}}
$$

em que ETp é a evapotranspiração potencial $\left(\mathrm{mm} \mathrm{dia}^{-1}\right) ; \mathrm{C}_{\mathrm{j}}$ é o fator de correção, que varia em função do número de dias do mês considerado; $\mathrm{a}_{\mathrm{i}}$ é a função cúbica do índice anual de calor e I é o índice de calor obtido pela soma dos 12 índices mensais (i).

Coeficientes decendiais do cultivo $(\mathrm{Kc})$ : Este coeficiente corresponde à relação entre a evapotranspiração máxima (ETm) e a evapotranspiração potencial (ETp); Kcs são determinados por médias decendiais para cada fase e gerados pela interpolação dos dados para as fases fenológicas definidas por Doorenbos \& Kassam (1979):

$$
\mathrm{Kc}=\frac{\mathrm{ET}_{\mathrm{m}}}{\mathrm{ET}_{\mathrm{p}}}
$$

Ciclo das cultivares: Para representar as cultivares de feijão-caupi recomendadas para o Estado da Paraíba considerou-se apenas um ciclo de 70 dias (precoce), haja vista que a diferença entre as cultivares, quanto ao ciclo, é pouco variável (< 10\%). A definição e a duração das fases fenológicas foram estabelecidas da seguinte forma: i) fase I - da semeadura até $10 \%$ do desenvolvimento vegetativo (DV) (15 dias); ii) fase II - de $10 \%$ do DV até a floração (20 dias); iii) da floração até o enchimento das vagens (EV) (20 dias) e iv) do EV até a maturação (15 dias). Lançou-se mão dos valores de Kc da cultura na base decendial ao longo do ciclo da cultura de feijão-caupi (Andrade Júnior et al., 2001) e se estabeleceu uma classe média de CAD, denominada Tipo 1 - média capacidade de armazenamento de água $(\mathrm{CAD}=40 \mathrm{~mm})$ associado ao solo do tipo Latossolos Vermelho-Amarelo e Vermelho-Escuro (com menos de $35 \%$ de argila).

Datas de simulação: Estipularam-se da seguinte forma: 30 dias antes do plantio e 30 dias após a colheita, para os intervalos de plantio de 10 dias. Os balanços hídricos foram determinados no período compreendido entre 1 de janeiro a 31 de maio.

\section{Variáveis de saída do modelo}

Índice de satisfação da necessidade de água para a cultura (ISNA): Definido como a razão entre a evapotranspiração real e a evapotranspiração máxima (ETr/ETm) ao longo do ciclo, para determinado ano, em certa data e em determinado tipo de solo, para a leguminosa de ciclo médio. Como o ciclo da cultura foi dividido em quatro fases fenológicas e a fase de enchimento das vagens é o período mais determinante da 
produtividade final, estima-se o valor de ISNA nesta fase. A partir deste cálculo, se estabeleceu a função de frequência do ISNA e se selecionou a data em que o valor calculado é maior ou igual ao critério de risco adotado (ISNA $\geq 0,50$ ), em $80 \%$ dos casos; para a caracterização do risco climático obtido ao longo dos períodos de simulação se estabeleceram três classes de ISNA, conforme (Amaral et al., 2005):

ISNA $\geq 0,50:$ a cultura do feijão-caupi de sequeiro está exposta a um baixo risco climático.

$0,40 \leq$ ISNA < 0,50: a cultura do feijão-caupi de sequeiro está exposta a um risco climático médio.

- ISNA < 0,40: a cultura do feijão-caupi de sequeiro está exposta a um alto risco climático.

Adotaram-se, para espacialização dos resultados, os seguintes procedimentos: digitação de arquivo de pontos (em formato ASCII) arranjados em três colunas, com latitude, longitude e valores de relação ISNA, com $80 \%$ de frequência de ocorrência; transformação das coordenadas geográficas em coordenadas de projeção cartográfica (no caso, projeção policônica); leitura do arquivo de pontos; organização das amostras e geração de uma grade regular (grade retangular, regularmente espaçada de pontos em que o valor da cota de cada ponto é estimado a partir da interpolação de um número de vizinhos mais próximos). Por se tratar de uma análise bidimensional, na qual as variações de ISNA foram espacializadas em função do tempo e se desconsiderando os efeitos orográficos, o interpolador escolhido foi aquele que mais se aproximou de um resultado linear.

\section{RESULTADOS E DISCUSSÃO}

A Figura 1 apresenta as áreas favoráveis para a cultura do feijão-caupi no Estado da Paraíba, em condições atuais de temperatura e com os acréscimos de 3 e $6{ }^{\circ} \mathrm{C}$ para o segundo decêndio do mês de janeiro. As áreas de inaptidão da cultura estudada aumentaram significativamente com o aumento da temperatura do ar. As mudanças são mais acentuadas quando se compara a condição climática atual (Figura 1A) com o aumento de temperatura do ar de $3{ }^{\circ} \mathrm{C}$ (Figura 1B) do que quando se comparam os cenários de aumento de temperatura do ar de 3 para $6{ }^{\circ} \mathrm{C}$ (Figura $1 \mathrm{~B}$ e $1 \mathrm{C}$ ). Para o plantio no mês de janeiro e independentemente do cenário climático, as mesorregiões situadas mais a oeste do Estado se apresentam como as áreas mais favoráveis ao cultivo do feijão-caupi em comparação com o restante da área de estudo; entretanto, para os dois cenários traçados com acréscimo de temperatura, grande parte dessa área se torna desfavorável ao plantio da cultura após o primeiro decêndio de fevereiro (Figura 2B e 2C).

A Tabela 1 evidencia que o potencial atual de cultivo do feijão-caupi para a mesorregião do Sertão apresenta menor risco climático no período de 21 a 31 de janeiro, com área favorável de $11.108 \mathrm{~km}^{2}$, ou seja, 48,9\% de área total da mesorregião; por outro lado, com o aumento médio da temperatura do ar de $3{ }^{\circ} \mathrm{C}$, a área apta ao cultivo do feijão-caupi passa a ser $4.752 \mathrm{~km}^{2}$, provocando uma redução superior a $50 \%$ em relação à área atual. No cenário de condições extremas em
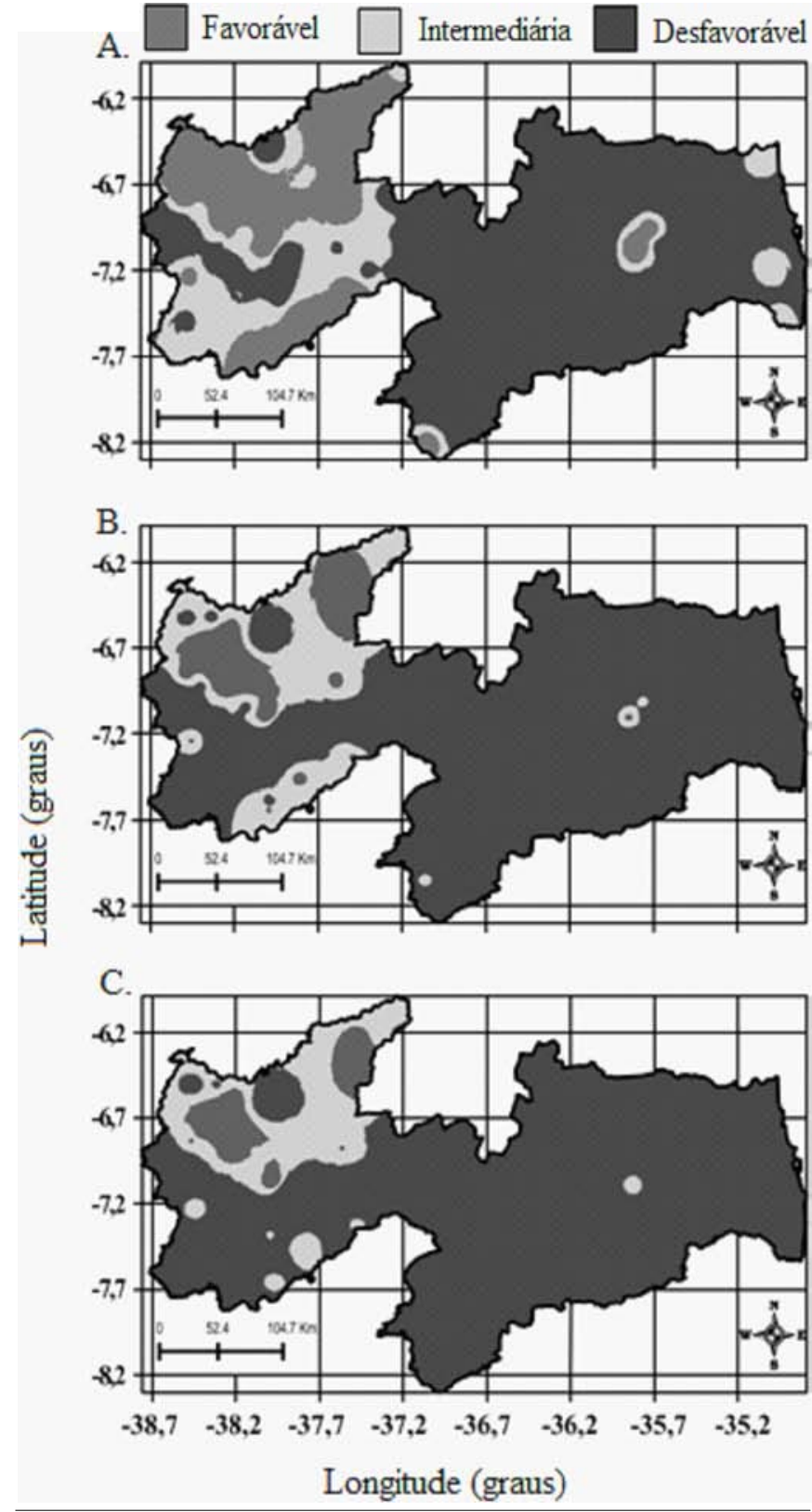

Figura 1. Espacial ização do índice de satisfação da necessidade de água para a cultura para semeadura do feijão-caupi de sequeiro em 15 dejaneiro, nas condições atuais de temperatura do ar $(A)$, com acréscimo de temperatura de $3 \stackrel{\circ}{\circ} \mathrm{C}(\mathrm{B})$ e de $6 \stackrel{\circ}{ } \mathrm{C}(\mathrm{C})$

que se considera o aumento de temperatura do ar de $6{ }^{\circ} \mathrm{C}$, a área favorável ao plantio fica sendo apenas $3.366 \mathrm{~km}^{2}$, isto é, $14,8 \%$ da área da mesorregião em comparação com a situação atual; para a mesorregião do Sertão, o período de semeadura é bastante restrito fazendo com que a escolha certa para o plantio seja fator determinante no sucesso da produção. De acordo com os cenários propostos, é evidente a tendência de redução das áreas com menores riscos climáticos em que, a partir do segundo decêndio do mês de fevereiro, praticamente o cultivo do caupi se tornará impraticável na região.

Mesmo nas condições atuais de temperatura do ar, nas datas de 5 de fevereiro (Figura 2A) e 25 de março (Figura 3A), grande parte do Estado da Paraíba apresenta de médio a alto risco climático associado ao cultivo do feijão-caupi. As me- 
Tabela 1. Distribuição das áreas (\%) de alto (AR), médio (MR) e baixo risco (BR) climático ao cultivo do feijão-caupi no Estado da Paraíba para a mesorregião do Sertão do Estado, nas diferentes datas de semeadura simuladas nas condições atuais de temperatura e com 0 acréscimo de 3 e $6 \stackrel{\circ}{C}$

\begin{tabular}{|c|c|c|c|c|c|c|c|c|c|}
\hline \multirow{3}{*}{$\begin{array}{l}\text { Mesorregião } \\
\text { Períodos de } \\
\text { semeadura }\end{array}$} & \multicolumn{9}{|c|}{ Sertão } \\
\hline & AR & MR & BR & AR & MR & BR & AR & MR & BR \\
\hline & \multicolumn{3}{|c|}{ Condições atuais } & \multicolumn{3}{|c|}{ Acréscimo de $3 \stackrel{\circ}{-C}$} & \multicolumn{3}{|c|}{ Acréscimo de $6 \stackrel{\circ}{\circ}$} \\
\hline 10 a $10 / 01$ & 76,7 & 16,4 & 6,8 & 88,8 & 9,0 & 2,1 & 93,3 & 5,7 & 1,0 \\
\hline 11 a $20 / 01$ & 20,5 & 30,6 & 48,9 & 49,2 & 29,9 & 20,9 & 55,5 & 29,7 & 14,8 \\
\hline 21 a 31 / 01 & 1,7 & 7,2 & 91,1 & 9,0 & 42,9 & 48,1 & 30,5 & 46,9 & 22,7 \\
\hline 10 a $10 / 02$ & 10,3 & 55,5 & 34,2 & 46,9 & 50,0 & 3,1 & 91,5 & 8,5 & 0,1 \\
\hline 11 a $20 / 02$ & 73,9 & 22,1 & 4,0 & 96,5 & 2,9 & 0,6 & 98,3 & 1,5 & 0,2 \\
\hline 21 a 28 / 02 & 58,7 & 35,6 & 5,6 & 96,2 & 3,8 & 0,0 & 100,0 & 0,0 & 0,0 \\
\hline 10 a $10 / 03$ & 81,7 & 14,9 & 3,4 & 96,9 & 2,8 & 0,3 & 100,0 & 0,0 & 0,0 \\
\hline 11 a $20 / 03$ & 93,6 & 5,8 & 0,7 & 100,0 & 0,0 & 0,0 & 100,0 & 0,0 & 0,0 \\
\hline 21 a 31 / 03 & 99,8 & 0,2 & 0,0 & 100,0 & 0,0 & 0,0 & 100,0 & 0,0 & 0,0 \\
\hline 10 a $10 / 04$ & 100,0 & 0,0 & 0,0 & 100,0 & 0,0 & 0,0 & 100,0 & 0,0 & 0,0 \\
\hline 11 a $20 / 04$ & 100,0 & 0,0 & 0,0 & 100,0 & 0,0 & 0,0 & 100,0 & 0,0 & 0,0 \\
\hline 21 a $30 / 04$ & 100,0 & 0,0 & 0,0 & 100,0 & 0,0 & 0,0 & 100,0 & 0,0 & 0,0 \\
\hline 10 a $10 / 05$ & 100,0 & 0,0 & 0,0 & 100,0 & 0,0 & 0,0 & 100,0 & 0,0 & 0,0 \\
\hline 11 a $20 / 05$ & 100,0 & 0,0 & 0,0 & 100,0 & 0,0 & 0,0 & 100,0 & 0,0 & 0,0 \\
\hline 21 a $31 / 05$ & 100,0 & 0,0 & 0,0 & 100,0 & 0,0 & 0,0 & 100,0 & 0,0 & 0,0 \\
\hline
\end{tabular}

sorregiões do Sertão e Borborema do Estado são as que concentram as maiores áreas desfavoráveis para o plantio, tornando-as de pouca expressão na produção do caupi, ainda mais com o aumento da temperatura média do ar de 3 (Figura $2 \mathrm{~B}$ e $3 \mathrm{~B}$ ) e $6^{\circ} \mathrm{C}$ (Figura $2 \mathrm{C}$ e $3 \mathrm{C}$ ); tal aumento de temperatura do ar promove grandes alterações nas regiões consideradas favoráveis para o cultivo fazendo com que a maior oferta de áreas aptas ao cultivo se concentre nas mesorregiões do Agreste e Zona da Mata paraibana.

Tabela 2. Distribuição das áreas (\%) de alto (AR), médio (MR) e baixo risco (BR) climático ao cultivo do feijão-caupi no Estado da Paraíba para a mesorregião da Borborema do Estado, nas diferentes datas de semeadura simuladas nas condições atuais de temperatura e com os acréscimo de 3 e $6 \stackrel{\circ}{\circ}$

\begin{tabular}{|c|c|c|c|c|c|c|c|c|c|}
\hline \multirow{3}{*}{$\begin{array}{l}\text { Mesorregião } \\
\text { Períodos de } \\
\text { semeadura }\end{array}$} & \multicolumn{9}{|c|}{ Borborema } \\
\hline & AR & MR & BR & AR & MR & BR & AR & MR & BR \\
\hline & \multicolumn{3}{|c|}{ Condições atuais } & \multicolumn{3}{|c|}{ Acréscimo de $3^{\circ} \mathrm{C}$} & \multicolumn{3}{|c|}{ Acréscimo de 6 ? } \\
\hline 10 a $10 / 01$ & 100,0 & 0,0 & 0,0 & 100,0 & 0,0 & 0,0 & 100,0 & 0,0 & 0,0 \\
\hline 11 a $20 / 01$ & 96,2 & 2,4 & 1,4 & 100,0 & 0,0 & 0,0 & 100,0 & 0,0 & 0,0 \\
\hline 21 a $31 / 01$ & 85,9 & 8,6 & 5,5 & 95,7 & 4,1 & 0,1 & 98,5 & 1,5 & 0,0 \\
\hline 10 a $10 / 02$ & 82,3 & 12,9 & 4,8 & 95,4 & 4,0 & 0,6 & 100,0 & 0,0 & 0,0 \\
\hline 11 a $20 / 02$ & 95,6 & 4,1 & 0,3 & 99,7 & 0,3 & 0,0 & 100,0 & 0,0 & 0,0 \\
\hline 21 a $28 / 02$ & 95,3 & 4,7 & 0,0 & 100,0 & 0,0 & 0,0 & 100,0 & 0,0 & 0,0 \\
\hline 10 a $10 / 03$ & 94,1 & 5,6 & 0,2 & 100,0 & 0,0 & 0,0 & 100,0 & 0,0 & 0,0 \\
\hline 11 a $20 / 03$ & 99,9 & 0,1 & 0,0 & 100,0 & 0,0 & 0,0 & 100,0 & 0,0 & 0,0 \\
\hline 21 a $31 / 03$ & 100,0 & 0,0 & 0,0 & 100,0 & 0,0 & 0,0 & 100,0 & 0,0 & 0,0 \\
\hline 10 a $10 / 04$ & 98,6 & 1,4 & 0,0 & 100,0 & 0,0 & 0,0 & 100,0 & 0,0 & 0,0 \\
\hline 11 a $20 / 04$ & 98,9 & 1,1 & 0,0 & 100,0 & 0,0 & 0,0 & 100,0 & 0,0 & 0,0 \\
\hline 21 a $30 / 04$ & 97,6 & 2,1 & 0,3 & 100,0 & 0,0 & 0,0 & 100,0 & 0,0 & 0,0 \\
\hline 10 a $10 / 05$ & 97,6 & 1,6 & 0,8 & 100,0 & 0,0 & 0,0 & 100,0 & 0,0 & 0,0 \\
\hline 11 a $20 / 05$ & 98,2 & 1,1 & 0,7 & 98,6 & 0,9 & 0,5 & 100,0 & 0,0 & 0,0 \\
\hline 21 a $31 / 05$ & 98,4 & 1,4 & 0,2 & 98,8 & 1,0 & 0,2 & 100,0 & 0,0 & 0,0 \\
\hline
\end{tabular}
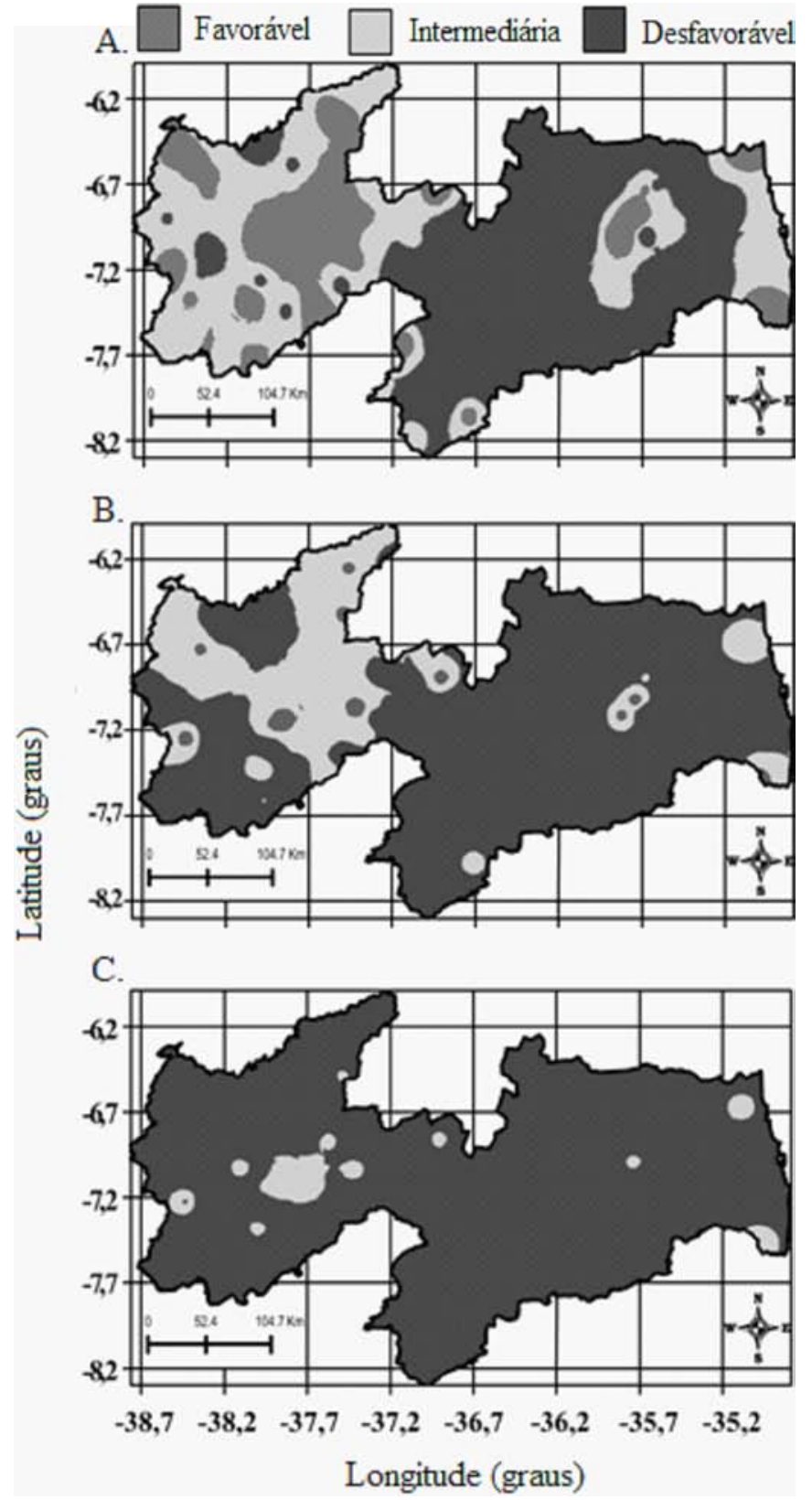

Figura 2. Espacial ização do índice de satisfação da necessidade de água para a cultura para semeadura do feijão-caupi de sequeiro em 05 de fevereiro, nas condições atuais de temperatura do ar (A), com acréscimo de temperatura de $3 \stackrel{\circ}{\circ}$ (B) e de $6 \stackrel{\circ}{\circ}$ (C)

A Tabela 2 exibe a distribuição das áreas de alto, médio e baixo risco climático na mesorregião da Borborema do Estado da Paraíba. No início do ano o cultivo de feijão nesta mesorregião é totalmente inapropriado, tanto nas condições climáticas atuais como nos cenários estudados; nas demais épocas do período de semeadura, a cultura no Estado da Paraíba, continua apresentando alto risco climático, principalmente para os cenários com aumento de temperatura do ar de 3 e $6{ }^{\circ} \mathrm{C}$; com o aumento de temperatura do ar de 3 e $6{ }^{\circ} \mathrm{C}$, o alto risco de $100 \%$ ocorre praticamente em todo o período de semeadura, sobretudo no cenário de acréscimo de temperatura do ar de $6{ }^{\circ} \mathrm{C}$, em que apenas o decêndio de 21 a 31 de janeiro não apresenta $100 \%$ de risco climático. 

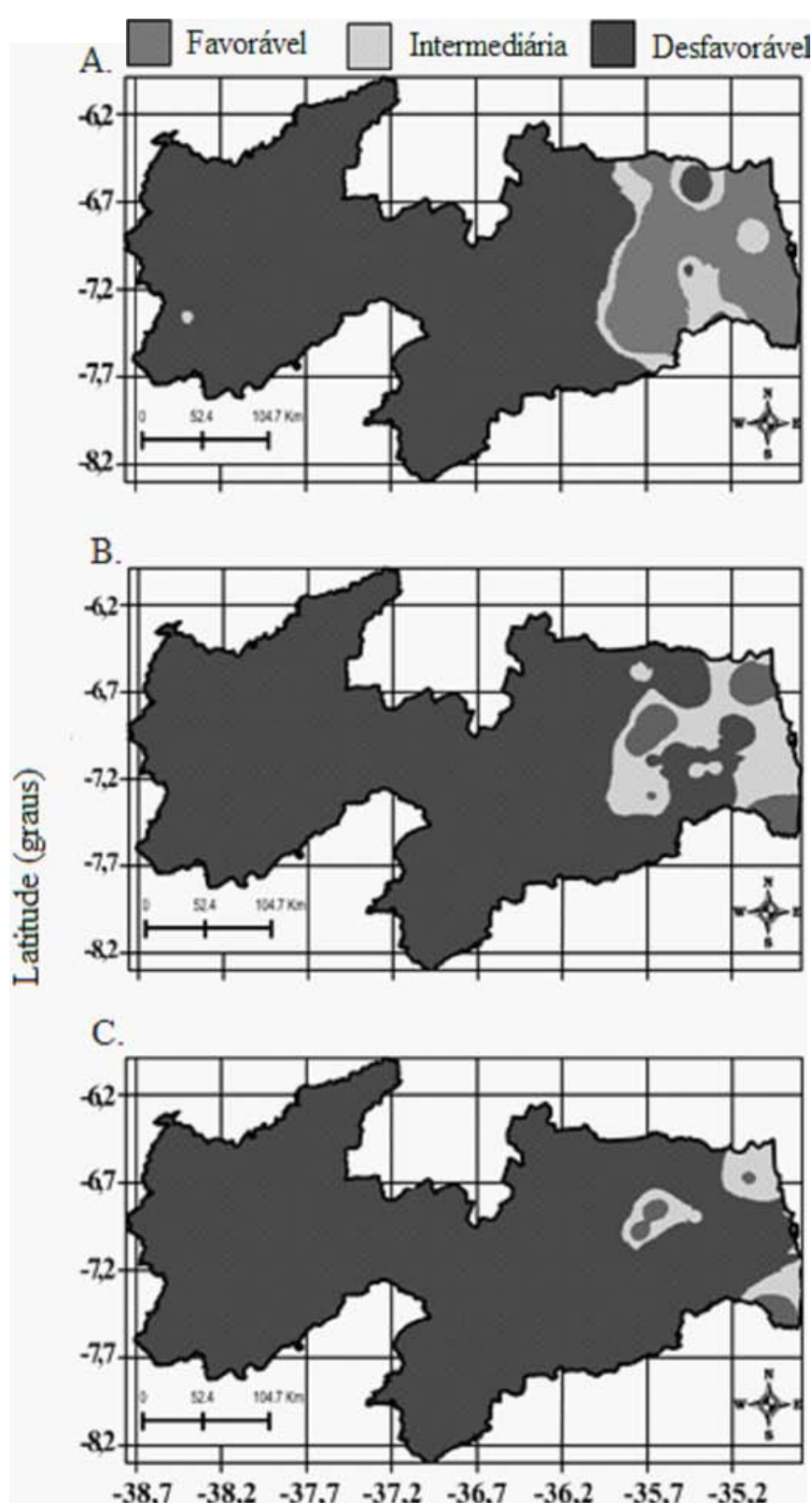

Longitude (graus)

Figura 3. Espacial ização do índice de satisfação da necessidade de água para a cultura para semeadura do feijão-caupi de sequeiro em 25 de março, nas condições atuais de temperatura do ar (A), com acréscimo de temperatura de 3 ํ $\mathrm{C}$ (B) e de $6 \stackrel{\circ}{ } \stackrel{(C)}{ }$

Mais ainda, com o aumento na temperatura do ar nas próximas décadas, a agricultura de sequeiro continua sendo prática de alto risco no semiárido brasileiro; desta forma, a identificação de áreas que apresentam maior potencial de produção e estejam expostas ao menor risco climático possível, é imprescindível para a inserção de qualquer cultura, seja no âmbito da agricultura familiar ou voltada para os grandes produtores. Neste estudo se identificaram as mesorregiões do Agreste e Zona da Mata no Estado da Paraíba nas quais, possivelmente, o cultivo do feijão-caupi apresenta as maiores condições de se obter os máximos potenciais produtivos. A Tabela 3 mostra o potencial atual de cultivo do feijão-caupi para a mesorregião do Agreste com vistas às condições atu-
Tabela 3. Distribuição das áreas (\%) de alto (AR), médio (MR) e baixo risco (BR) climático ao cultivo do feijão-caupi no Estado da Paraíba para a mesorregião do Agreste do Estado, nas diferentes datas de semeadura simuladas nas condições atuais de temperatura e com acréscimo de 3 e $6 \stackrel{\circ}{ } \mathrm{C}$

\begin{tabular}{|c|c|c|c|c|c|c|c|c|c|}
\hline \multirow{2}{*}{$\begin{array}{l}\text { Mesorregião } \\
\text { Períodos de }\end{array}$} & \multicolumn{9}{|c|}{ Agreste } \\
\hline & AR & MR & BR & AR & MR & BR & AR & MR & BR \\
\hline semeadura & \multicolumn{3}{|c|}{ Condições atuais } & \multicolumn{3}{|c|}{ Acréscimo de $3 \stackrel{\circ}{\circ} \mathrm{C}$} & \multicolumn{3}{|c|}{ Acréscimo de 6 ㄷ } \\
\hline 10 a $10 / 01$ & 99,8 & 0,2 & 0,0 & 100,0 & 0,0 & 0,0 & 100,0 & 0,0 & 0,0 \\
\hline 11 a $20 / 01$ & 93,8 & 3,3 & 3,0 & 100,0 & 0,0 & 0,0 & 100,0 & 0,0 & 0,0 \\
\hline 21 a 31 / 01 & 91,3 & 4,4 & 4,3 & 96,8 & 2,5 & 0,7 & 100,0 & 0,0 & 0,0 \\
\hline 10 a $10 / 02$ & 78,7 & 15,6 & 5,7 & 95,3 & 3,9 & 0,8 & 100,0 & 0,0 & 0,0 \\
\hline 11 a $20 / 02$ & 63,2 & 24,4 & 12,4 & 94,6 & 4,7 & 0,7 & 100,0 & 0,0 & 0,0 \\
\hline 21 a 28 / 02 & 56,1 & 25,1 & 18,7 & 87,3 & 12,2 & 0,5 & 100,0 & 0,0 & 0,0 \\
\hline 10 a $10 / 03$ & 56,7 & 30,0 & 13,3 & 91,9 & 7,5 & 0,6 & 100,0 & 0,0 & \\
\hline 11 a $20 / 03$ & 63,3 & 18,6 & 18,0 & 85,7 & 9,9 & 4,5 & 94,0 & 5,5 & 0,6 \\
\hline 21 a $31 / 03$ & 47,9 & 17,7 & 34,4 & 72,6 & 20,6 & 6,8 & 90,8 & 6,5 & 2,8 \\
\hline 10 a $10 / 04$ & 34,8 & 6,4 & 58,8 & 43,7 & 26,1 & 30,1 & 59,5 & 26,1 & 14,4 \\
\hline 11 a $20 / 04$ & 31,0 & 10,6 & 58,3 & 45,6 & 18,5 & 35,9 & 64,4 & 21,7 & 13,8 \\
\hline 21 a $30 / 04$ & 29,6 & 13,4 & 57,0 & 36,0 & 17,5 & 46,6 & 58,2 & 20,9 & 20,8 \\
\hline 10 a $10 / 05$ & 30,8 & 11,8 & 57,5 & 42,9 & 21,4 & 35,7 & 70,6 & 15,4 & 14,0 \\
\hline 11 a $20 / 05$ & 48,4 & 14,8 & 36,8 & 51,5 & 20,3 & 28,3 & 80,6 & 14,9 & 4,5 \\
\hline 21 a 31 / 05 & 43,6 & 15,8 & 40,6 & 52,4 & 18,7 & 28,9 & 75,0 & 14,3 & 10,7 \\
\hline
\end{tabular}

ais de temperatura do ar e de acréscimo de 3 e $6^{\circ} \mathrm{C}$; na situação climática atual, o menor risco climático ocorre no terceiro decêndio do mês de abril, com uma área favorável de 7.364 $\mathrm{km}^{2}$, ou seja, $57,0 \%$ da área total da mesorregião; por outro lado, com o aumento médio da temperatura do ar de $3{ }^{\circ} \mathrm{C}$, a área apta ao cultivo do feijão-caupi passa a ser $6.012 \mathrm{~km}^{2}$, provocando redução da ordem de $20 \%$ da área atual. No caso extremo e se considerando o aumento de temperatura do ar de $6{ }^{\circ} \mathrm{C}$, a área favorável ao plantio fica sendo apenas de 2.690 $\mathrm{km}^{2}$, ou seja, $20,8 \%$ da área da mesorregião, em comparação com a situação atual; para a mesorregião do Agreste, o período de semeadura é bem superior quando comparado com o das mesorregiões do Sertão e Borborema.

Ainda é possível inferir que a época de semeadura segue a dinâmica da precipitação pluvial no Estado, uma vez que, para esta mesorregião, a atuação de sistemas atmosféricos produtores de chuva é mais frequente no terceiro decêndio do mês de março e se estende até meados de julho. Especificamente, a Zona de Convergência Intertropical (ZCIT) e ondas de leste estão presentes na região, fazendo com que a oferta hídrica seja maior no referido período diminuindo, assim, o risco climático por estresse hídrico.

$\mathrm{O}$ acréscimo na temperatura do ar atua de forma direta no aumento da evapotranspiração provocando maior deficiência hídrica, de modo a diminuir os intervalos de menor risco climático nas regiões produtoras, restringindo ainda mais as áreas favoráveis à inserção da cultura no Estado.

Na mesorregião da Zona da Mata a oferta hídrica é bem maior quando comparada com as demais mesorregiões do Estado (Tabela 4). O período considerado favorável à semeadura do feijão-caupi se estende do segundo decêndio do mês de março até o terceiro decêndio do mês de maio. Quando comparado com o cenário de condições atuais (Figura 4A) com o acréscimo de $3{ }^{\circ} \mathrm{C}$ (Figura 4B) na temperatura do ar 

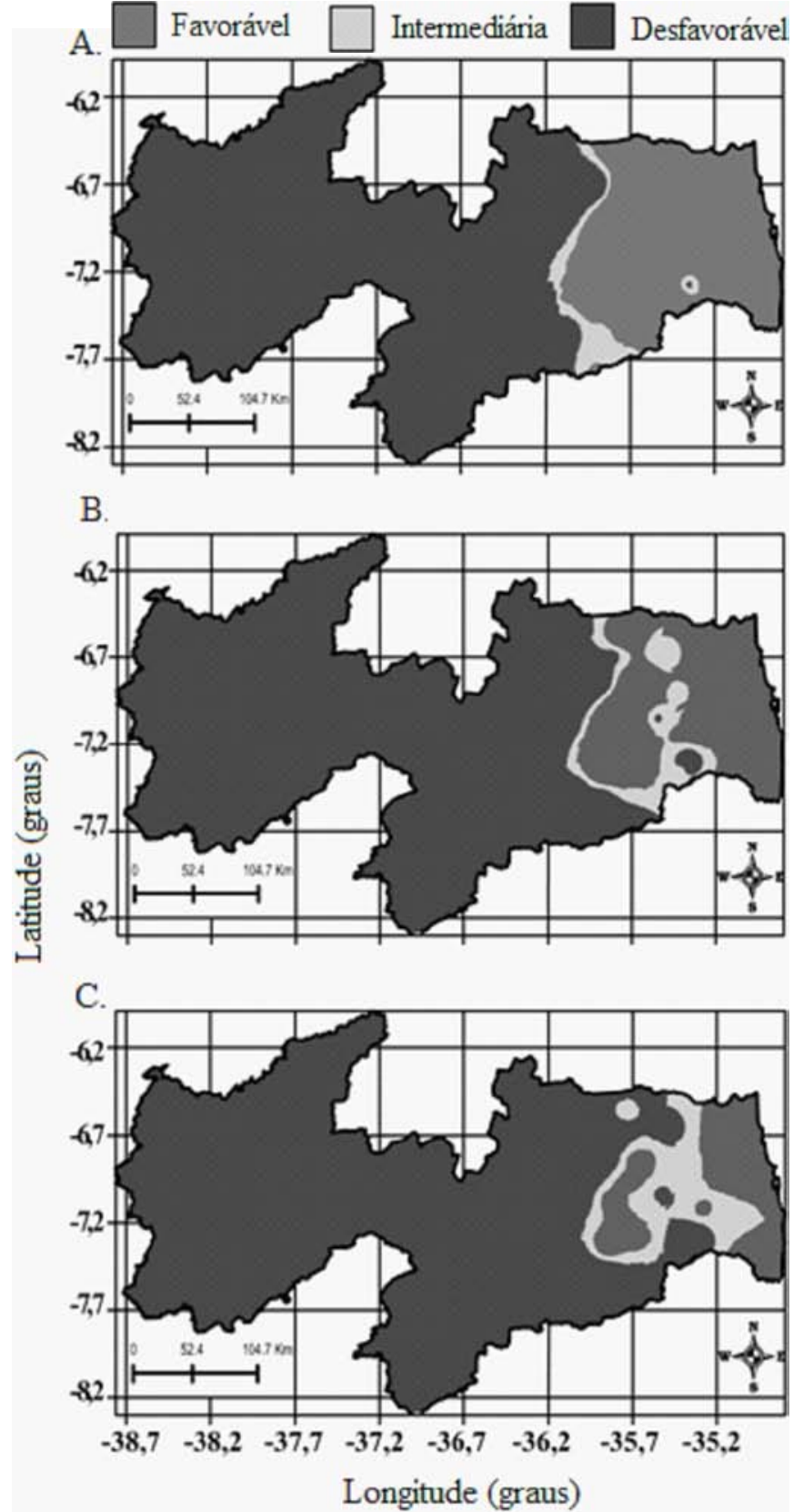

Figura 4. Espacial ização do índice de satisfação da necessidade de água para a cultura para semeadura do feijão-caupi de sequeiro em 15 de abril, nas condições atuais de temperatura do ar (A), com acréscimo de temperatura de $3 \stackrel{\circ}{\circ}$ (B) e de $6 \stackrel{\circ}{\circ}(\mathrm{C})$

resulta no decréscimo de 98,2 para 88,5\% nas áreas com baixo risco climático do cultivo do feijão -caupi no segundo decêndio de abril; por outro lado, com o acréscimo de $6{ }^{\circ} \mathrm{C}$ (Figura 4C), este decréscimo é de 9,7\%, ou seja, a área favorável decresce de $5.137 \mathrm{~km}^{2}$ para $4.632 \mathrm{~km}^{2}$ da área total da mesorregião. Nas condições climáticas atuais se recomenda, a fim de garantir a produtividade nessa mesorregião do Estado, o cultivo do caupi no período de maio a junho a fim de que o período de colheita ocorra com temperaturas mais elevadas e em condições de menor umidade, evitando a ação de organismos patogênicos.

Tem-se, na Figura 5 as áreas favoráveis para a cultura do feijão-caupi no Estado da Paraíba, em condições atuais de
Tabela 4. Distribuição das áreas (\%) de alto (AR), médio (MR) e baixo risco (BR) climático ao cultivo do feijão-caupi no Estado da Paraíba para a mesorregião da Zona da Mata do Estado, nas diferentes datas de semeadura simuladas nas condições atuais de temperatura e com os acréscimo de 3 e $6 \stackrel{\circ}{ } C$

\begin{tabular}{|c|c|c|c|c|c|c|c|c|c|}
\hline \multirow{3}{*}{$\begin{array}{l}\text { Mesorregião } \\
\text { Períodos de } \\
\text { semeadura }\end{array}$} & \multicolumn{9}{|c|}{ Zona da Mata } \\
\hline & AR & MR & BR & AR & MR & BR & AR & MR & BR \\
\hline & \multicolumn{3}{|c|}{ Condições atuais } & \multicolumn{3}{|c|}{ Acréscimo de $3 \stackrel{\circ}{\circ}$} & \multicolumn{3}{|c|}{ Acréscimo de 6 ㅇ } \\
\hline 10 a $10 / 01$ & 90,8 & 4,2 & 5,0 & 93,1 & 6,5 & 0,4 & 94,7 & 5,3 & 0,0 \\
\hline 11 a $20 / 01$ & 76,9 & 23,1 & 0,0 & 100,0 & 0,0 & 0,0 & 100,0 & 0,0 & 0,0 \\
\hline 21 a 3 & 59,7 & 33,9 & 6,4 & 89,1 & 10,9 & 0,0 & 92,5 & 7,5 & 0,0 \\
\hline 10 a $10 / 02$ & 44,9 & 35,8 & 19,3 & 79,2 & 16,6 & 4,2 & 86,9 & 13,1 & 0,0 \\
\hline 11 a $20 / 02$ & 13,7 & 63,2 & 23,0 & 81,0 & 19,0 & 0,0 & 96,0 & 4,0 & 0,0 \\
\hline 21 a 2 & 50,4 & 44,6 & 4,9 & 82,2 & 17,8 & 0,0 & 100,0 & 0,0 & 0,0 \\
\hline 10 a $10 / 03$ & 53,0 & 27,4 & 19,7 & 78,1 & 10,7 & 11,2 & 81,9 & 13,5 & 4,6 \\
\hline 11 a $20 / 03$ & 8,3 & 56,8 & 34,9 & 63,3 & 21,5 & 15,2 & 76,6 & 14,9 & 8,5 \\
\hline 21 a 31 / 03 & 2,7 & 15,7 & 81,6 & 33,7 & 45,4 & 20,9 & 71,4 & 17,5 & 11,2 \\
\hline 10 a $10 / 04$ & 0,0 & 1,1 & 98,9 & 3,8 & 41,4 & 54,8 & 9,2 & 65,1 & 25,7 \\
\hline 11 a $20 / 04$ & 0,2 & 1,6 & 98,2 & 4,1 & 7,4 & 88,5 & 9,1 & 32,5 & 58,4 \\
\hline 21 a $30 / 04$ & 1,0 & 2,1 & 96,9 & 5,5 & 14,0 & 80,6 & 14,7 & 26,8 & 58,4 \\
\hline 10 a $10 / 05$ & 0,0 & 0,4 & 99,6 & 5,7 & 15,7 & 78,6 & 15,9 & 28,0 & 56,0 \\
\hline 11 a $20 / 05$ & 0,5 & 4,8 & 94,7 & 9,4 & 19,4 & 71,3 & 25,5 & 53,9 & 20,6 \\
\hline 21 a $31 / 05$ & 0,3 & 3,9 & 95,7 & 9,7 & 48,6 & 41,7 & 43,8 & 44,7 & 11,5 \\
\hline
\end{tabular}

temperatura de ar (Figura 5A) com aumento de temperatura média de 3 (Figura 5B) e $6{ }^{\circ} \mathrm{C}$ (Figura 5C). Verifica-se o deslocamento da área com potencial produtivo para o leste do Estado. Na situação atual se observa uma área favorável entre as mesorregiões do Brejo e Litoral, com baixo risco climático, enquanto para o restante do Estado o alto risco é predominante. No cenário climático com o acréscimo de $3{ }^{\circ} \mathrm{C}$ na temperatura média do ar, o cultivo do caupi fica mais restrito, com muitas áreas apresentando alto e médio riscos (Figura 5B). No cenário com acréscimo de $6{ }^{\circ} \mathrm{C}$, as condições de plantio do feijão-caupi são mais pessimistas, haja vista que apenas as microrregiões do Estado próximas ao litoral passam a apresentar condições apropriadas para o seu cultivo (Figura 5C).

$\mathrm{O}$ aumento de temperatura de 3 para $6^{\circ} \mathrm{C}$, pode promover alterações nas regiões favoráveis ao cultivo do feijão-caupi, ficando evidente o deslocamento da área produtiva para as regiões de maior disponibilidade hídrica, tornando restrito o plantio desta cultura no Estado.

Nos dois cenários climáticos analisados, o aumento na temperatura do ar acentuará o abortamento de flores, que é um fator restritivo para a manutenção da produtividade do feijoeiro. Esses cenários podem ser contornados considerando-se duas situações: primeiro, se forem rapidamente implantadas práticas de manejo mitigadoras, que permitam aumentar o sequestro de carbono, reduzindo o efeito estufa. Neste particular, o trabalho de Moraes (2004), dentre outros, fortalece a constatação de que o aumento de temperatura do ar é evidente e se deve manejar as culturas de forma que elas se adaptem às novas condições climáticas; a segunda situação diz respeito ao melhoramento de plantas para adaptá-las aos estresses ambientais. Assim, para manter a produção do caupi no 


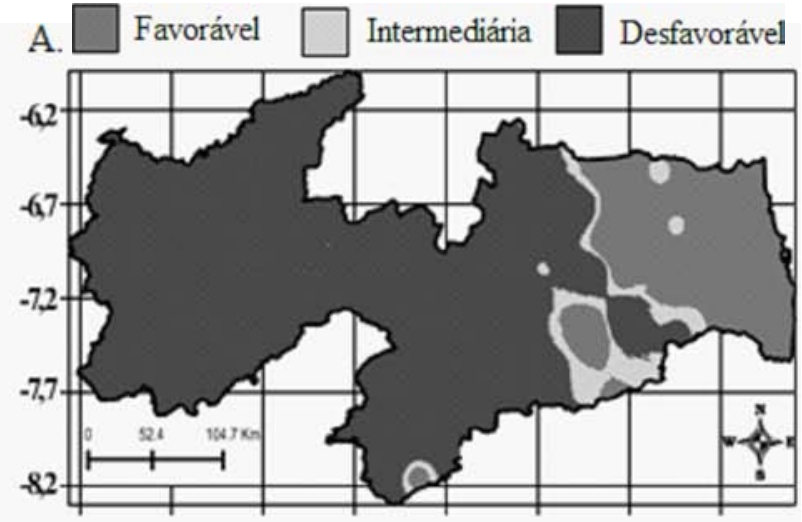

B.

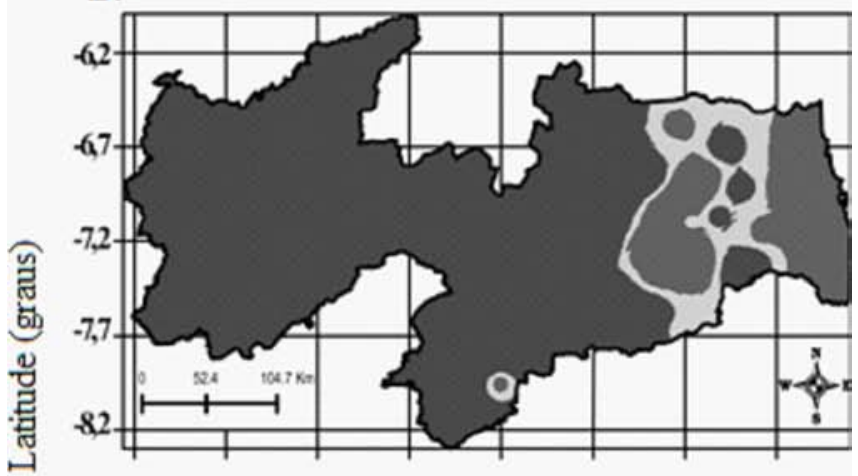

C.

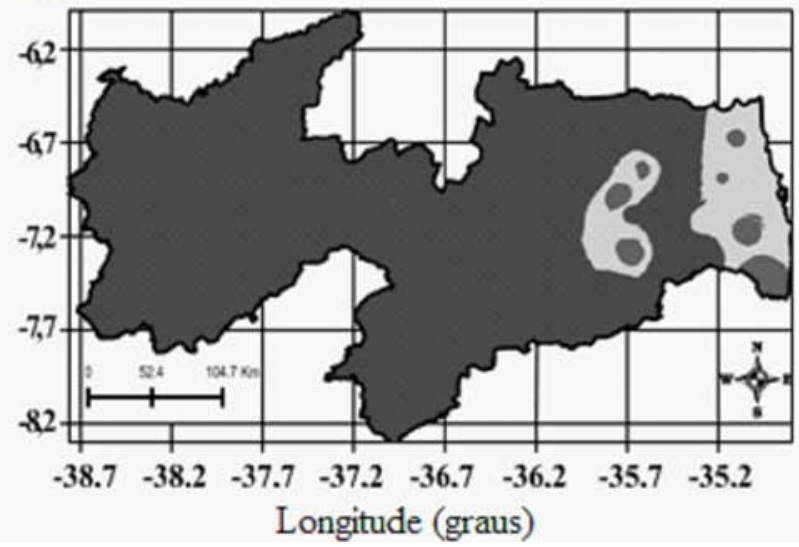

Figura 5. Espacial ização do índice de satisfação da necessidade de água para a cultura para semeadura do feijão-caupi de sequeiro em 15 de maio, nas condições atuais de temperatura do ar (A), com acréscimo de temperatura de $3 \stackrel{\circ}{\circ} \mathrm{C}(\mathrm{B})$ e de $6 \stackrel{\circ}{ }(\mathrm{C})$

Nordeste do Brasil e mais especificamente no Estado da Paraíba, nos próximos anos, tanto no que diz respeito à qualidade ou à quantidade, deve-se tomar medidas que levem em consideração a possibilidade da temperatura média do ar sofrer acréscimos acentuados.

\section{CONCLUSÕES}

1. Com o aumento da temperatura do ar de 3 e $6{ }^{\circ} \mathrm{C}$, como sugerido pelo IPCC, as áreas favoráveis ao cultivo do feijãocaupi no Estado da Paraíba serão reduzidas consideravelmente nas próximas décadas.
2. A restrição ao cultivo do feijão-caupi poderá atingir até $100 \%$ de algumas áreas do Estado da Paraíba, com aumento da temperatura do ar de $6{ }^{\circ} \mathrm{C}$.

3. Nos cenários estudados de aumento de temperatura do ar haverá o deslocamento das áreas de produção de feijãocaupi para regiões mais ao leste do Estado da Paraíba, onde a oferta hídrica é maior.

4. As mesorregiões do Agreste e Zona da Mata do Estado da Paraíba sofrerão as menores restrições ao cultivo do feijão em face do aumento da temperatura do ar, prevendo-se que, elas serão as únicas regiões produtoras da cultura em todo o Estado da Paraíba.

\section{LITERATURA CITADA}

Amaral, J. A. B.; Beltrão, N. E. de M.; Silva, M. T. Zoneamento agrícola do feijão-caupi no Nordeste Brasileiro: Safra 2005/ 2006, Estado da Paraíba. Campina Grande: Embrapa Algodão, 2005. p.1-9. Comunicado Técnico, 253

Andrade Júnior, A. S.; Bastos, E. A.; Cardoso, M. J.; Silveira Júnior, D. M. Zoneamento de risco climático para a cultura do milho no Estado do Maranhão. Revista Brasileira de Agrometeorologia, v.12, n.2, p.369-377, 2004.

Andrade Júnior, A. S.; Sentelhas, P. C.; Lima, M. G.; Aguiar, M. J. N.; Leite, D. A. S. R. Zoneamento agroclimático para as culturas de milho e de soja no Estado do Piauí. Revista Brasileira de Agrometeorologia, v.9, n.3, p.544-550, 2001.

Baron, C.; Perez, P.; Maraux, F. Sarrazon - Bilan hidrique applique au zonage. Paris: CIRAD, 1996. 26p.

Brasil. Ministério da Agricultura. Equipe de Pedologia e Fertilidade do Solo (Rio de Janeiro, RJ). Levantamento exploratório: Reconhecimento de solos do Estado da Paraíba. Rio de Janeiro: Ministério da Agricultura, 1972. v.1-2.

Câmara, G.; Souza, R. C. M.; Freitas, U. M.; Garrido, J. Spring: Integrating remote sensing and GIS by object-oriented data modeling. Computers and Graphies, v.20, n.3, p.395-403, 1996.

Cunha, R. G.; Assad, E. D. Uma visão geral sobre zoneamento agrícola Brasil. Revista Brasileira de Agrometeorologia, v.9, n.3, n.especial, p.377-385, 2001.

Doorenbos, J.; Kassam, A. H. Efectos del agua sobre el rendimiento de los cultivos. Rome: FAO, 1979. 212p. Estudio FAO. Riego y Drenaje, 33

Eagleman, A. M. An experimentaly derived model for actual evapotranspiration. Agricultural Meteorology, v.8, n.4/5, p.385409, 1971.

Ellis, R. H.; Lawer, R. J.; Summerfield, R. J.; Roberts, E. H.; Chay, P. M.; Brouwer, J. B.; Rose, J. L.; Yeates, S. J. Towards the reliable prediction on time to flowering in six annual crops. III. Cowpea (Vigna unguiculata). Experimental Agriculture, v.30, p.17-29, 1994.

Harrison, S. R.; Thornton, P. K.; Dent, J. B. The role of simulation experiments. Agrotechnology Transfer, v.9, n.8, p.10-11, 1989.

IBGE - Instituto Brasileiro de Geografia e Estatística: Produção agrícola municipal. http://www.sidra.ibge.gov.br/bda/tabelas. 25 Jun. 2008. 
IPCC - Intergovernmental Panel on Climate Change. Climate Change 2001: Impacts, adaptation, and vulnerability. Canziani, O. F.; Leary, N. A.; Dokken, D. J.; White, K. S.; McCarthy, J. J. (ed.) Cambridge: University Press, 2001. 1024p.

Jarvis, A.; Lane, A.; Hijmans, R. J. The effect of climate change on crop wild relatives. Agricultural, Ecosystems \& Environment, v.1, n.126, p.13-23, 2008.

Jones, P. G.; Thornton, P. K. The potential impacts of climate change on maize production in Africa and Latin America in 2055. Global Environmental Change. v.1, n.13, p.51-59, 2003.

Kenny, G. J.; Harrison, P. A. Thermal and moisture limits of grain maize in Europe: model testing and sensitivity to climate change. Climate Research, v.1, n.1, p.113-129, 1992.

Moraes, O. C. C. Ameaça na floresta submersa. Scientific American, n.24, 2004. www2.uol.com.br/sciam/conteudo/materia/ materia_44html. 15 Mai. 2008.

Silva, G. B. da; Azevedo, P. V. de. Potencial edafoclimático da "Chapada Diamantina" no Estado da Bahia para o cultivo de citrus. Revista Brasileira de Agrometeorologia, v.8, n.1, p.133-139, 2000.

Silva, M. T.; Amaral, J. A. B. Zoneamento de risco climático para a cultura do amendoim no Estado do Rio Grande do Norte. Revista de Biologia e Ciências da Terra, v.7, n.2, p.93-99, 2007.
Silva, V. de P. R. On climate variability in Northeast of Brazil. Journal of Arid Environments, v.1, n.58, p.575-596, 2004.

Silva, V. de P. R.; Belo Filho, A. F.; Silva, B. B. da; Campos; J. H. B. C. Desenvolvimento de um sistema de estimativa da evapotranspiração de referência. Revista Brasileira de Engenharia Agrícola e Ambiental, v.9, n.4, p.547-553, 2005.

Silva, V. de P. R.; Sousa, F. A. S.; Cavalcanti, E. P.; Souza, E. P.; Silva, B. B. Teleconnections between sea-surface temperature anomalies and air temperature in northeast Brazil. Journal of Atmospheric and Solar-Terrestrial Physics, v.68, n.1, p.781-792, 2006.

SUDENE - Superintendência do Desenvolvimento do Nordeste. Dados pluviométricos mensais do Nordeste. Recife: SUDENE, 1990. 239p.

Sultan, B.; Baron, C.; Dingkuhn, M.; Sarr, B.; Janicot, S. Agricultural impacts of large-scale variability of the West African monsoon. Agricultural and Forest Meteorology, v.1, n.128, p.93-110, 2005

Thornthwaite, C. W.; Mather, J. R. Instructions and tables for computing potential evapotranspiration and the water balance. Centerton: Drexel Institute of Technology Laboratory of Climatology, 1957. 311p.

Zullo Júnior, J.; Pinto, H. S.; Assad, E. D. Impact assessment study of climate change on agricultural zoning. Meteorological Applications, v.13, n.S1, p.69-80, 2006. 